\title{
CCCXIV. OESTRIOLGLUCURONIDE.
}

\author{
By SAUL LOUIS COHEN, GUY FREDERIC MARRIAN AND \\ ARTHUR DUSTON ODELL. \\ From the Department of Biochemistry, University of Toronto.
}

(Received 9 October 1936.)

Is a previous communication [Cohen \& Marrian, 1936], the isolation of a watersoluble substance containing a high proportion of combined oestriol was reported. Although no great confidence in the purity of this substance was felt, since it could not be isolated in a crystalline form, the suggestion was made on the basis of carbon and hydrogen analyses and certain colour reactions that it was an oestriolglucuronide. The method described for the isolation of this substance was long and tedious and the yields obtained were poor. Owing to the small amounts available it was not possible to study the properties of the substance in detail or to determine its physiological potency.

The method which has now been adopted for the isolation of the compound, although essentially similar to that originally described, is considerably shorter and results in excellent yields of a product of high purity. The steps in this modified method are shown in Table I. Attention may be drawn to the following points : (a) The neutralization of acid butanol extracts with ammonium hydroxide instead of sodium hydroxide. In this way high alkalinity of the evaporating extracts is more easily avoided. (b) Elimination of the extractions with $90 \%$ ethanol and $92 \%$ pyridine. Extraction of aqueous solutions with a 1:2 mixture of pyridine and benzene was used with some batches and was found to be a valuable method of purification in cases where the quantity of glucuronide in the urine was small. Good yields of a pure product, however, have been obtained without its help. (c) Elimination of the process in which a butanol solution was washed with $0.8 \%$ sodium carbonate and then extracted with $N / 50$ sodium hydroxide. In the present work it was found that the carbonate washing of the butanol caused very great losses of glucuronide. It is difficult to understand why this process gave such excellent results in the original work. (e) Crystallization of the final product as the sodium salt from methanol.

The crude products yielded by this process were recrystallized several times from methanol. When pure anhydrous methanol was employed, crystals melting at about $305^{\circ}$ and analysing excellently for $\mathrm{C}_{24} \mathrm{H}_{31} \mathrm{O}_{9} \mathrm{Na}, 0.5 \mathrm{CH}_{3} \mathrm{OH}$ were obtained. Methanol containing small amounts of water yielded a crystalline product melting at about $256^{\circ}$ and analysing for $\mathrm{C}_{24} \mathrm{H}_{31} \mathrm{O}_{9} \mathrm{Na}, 1.5 \mathrm{H}_{2} \mathrm{O} .{ }^{1}$ The highermelting product was found to be converted into the lower-melting one by treatment with water, while the reverse process could be effected by repeated crystallization from anhydrous methanol. It was not possible to remove either the methanol or water of crystallization by heating in vacuo at $80^{\circ}$ over phosphorus pentoxide.

1 It should be pointed out that owing to the decomposition that occurs at and just below the melting point in all these compounds, the exact thermometer reading varies considerably according to the rate of heating. Differences of 1 or $2^{\circ}$ in the melting points recorded for different preparations have therefore little significance. 
Table I.

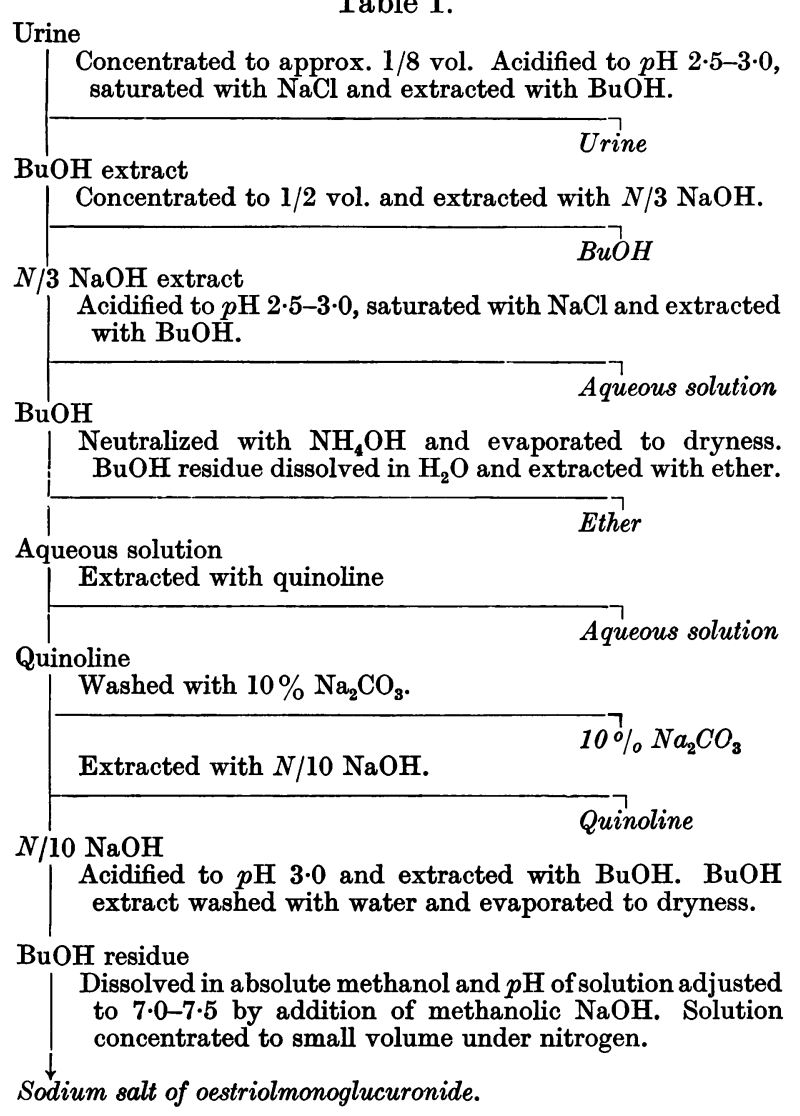

Acidification of aqueous solutions of the sodium salt yielded the free glucuronide in the form of a gel. Solid but amorphous preparations were obtained by dissolving the gel in alcohol and evaporating to dryness. Different preparations had sharp melting-points ranging from about $196^{\circ}$ to $236^{\circ}$. The different meltingpoints appeared to be caused by varying amounts of water of "crystallization". In the case of one preparation drying at $80^{\circ}$ in vacuo over $\mathrm{P}_{2} \mathrm{O}_{5}$ removed all the bound water, yielding a product which analysed correctly for the anhydrous glucuronide. With other preparations, however, it was not possible to obtain a completely anhydrous product by drying even at $140^{\circ}$. The reason for these differences is obscure and, since the question is of no great importance, the experimental results are not reported in full.

The crystalline sodium salt gave a strongly positive naphthoresorcinol test, a negative Benedict test before and a positive Benedict test after hydrolysis with dilute acid. Like most of the naturally occurring glucuronides, it is laevorotatory.

Millon's test was strongly positive in the cold. It was previously suggested, tentatively [Cohen \& Marrian, 1936], that this might indicate that the phenolic hydroxyl group of the oestriol was not conjugated with the glucuronic acid. Confirmation of this has now been obtained by $(a)$ spectrographic and $(b)$ chemical methods. 
(a) It has recently been shown by Callow [1936] that compounds of the oestrin series in which the phenolic group is free show a shift in absorption maximum from 2800 to $2950 \AA$. in the presence of alkali owing to salt formation. This shift of absorption maximum in alkaline solution was not observed in compounds of the oestrin series in which the phenolic hydroxyl was combined. Callow pointed out that use might be made of this observation in the determination of the structure of naturally occurring conjugated oestrogens such as oestriol glucuronide. Dr Callow has since very kindly examined spectrographically a specimen of the crystalline sodium salt and he has been able to show that in alkaline solution the shift in absorption maximum characteristic of a free phenolic hydroxyl does occur. The authors are grateful to Dr Callow for permission to include his results in the present paper.

(b) The glucuronide was methylated with methyl sulphate and alkali and the crude product hydrolysed with dilute acid. There was isolated from the hydrolysate a pure crystalline product which proved to be oestriol monomethyl ether. This provides the first strictly chemical evidence that oestriol is present in the complex, and since in oestriol monomethyl ether the phenolic hydroxyl is not free, it provides further proof that the phenolic hydroxyl group of oestriol is free in the glucuronide.

It was previously stated by Cohen et al. [1935] "that the precursor present in urine which gives rise to ether-soluble oestrin on treatment with acid has only a low oestrogenic potency when tested on ovariectomized mice". The significance of this fact in connexion with the assay of oestrin in urine was emphasized and attention was drawn to its possible physiological importance. Since the above statement was based on biological assays carried out with whole pregnancy urine, it was obviously of importance to determine the potency of the pure oestriolglucuronide. Assays on ovariectomized adult mice by the method of Marrian \& Parkes [1929] showed that the glucuronide had a potency of 370 m.u. per mg. Simultaneous tests with oestriol by an identical procedure showed a potency of $10,700 \mathrm{~m} . \mathrm{u}$. per $\mathrm{mg}$. The oestriol in the glucuronide has therefore only about $1 / 17$ of the potency of the same amount of oestriol in the uncombined state when assayed by the technique described.

An exact comparison of the potencies of oestriol and its glucuronide is not possible since, as can be seen in Fig. 2, the slopes of the two dose-response curves differ considerably and it seems likely therefore that the ratio of the potencies of the two compounds would vary significantly according to the method of assay. No marked differences could be observed in either the time of onset or the duration of the vaginal responses induced by the two substances.

\section{EXPERIMENTAL.}

Isolation of the sodium salt of oestriolglucuronide (batch 9).

30 litres of urine collected from women during the last 2 months of pregnancy were concentrated under reduced pressure at $70-80^{\circ}$ to about 4 litres. The mixture was saturated with sodium chloride, acidified to $p \mathrm{H} 2.5$ and extracted seven times with 1 litre volumes of butanol. Troublesome emulsions were broken by centrifuging. The combined butanol extracts were made slightly alkaline with $\mathrm{NH}_{4} \mathrm{OH}$, concentrated under reduced pressure to about 3 litres and extracted seven times with $500 \mathrm{ml}$. volumes of $\mathrm{N} / 3 \mathrm{NaOH}$. The combined alkaline extracts were saturated with $\mathrm{NaCl}$, acidified to $p \mathrm{H} 2.8$ and extracted five times with approximately $600 \mathrm{ml}$. volumes of butanol. The butanol extract was washed 
once with saturated aqueous $\mathrm{NaCl}$, made slightly alkaline with $\mathrm{NH}_{4} \mathrm{OH}$ and evaporated to dryness. The residue weighed $68 \mathrm{~g}$.

This material was dissolved in $200 \mathrm{ml}$. of water, and the solution, after

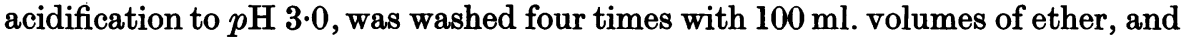
then extracted five times with approximately $50 \mathrm{ml}$. volumes of quinoline. The quinoline extract was washed four times with $50 \mathrm{ml}$. volumes of $10 \%$ aqueous $\mathrm{Na}_{2} \mathrm{CO}_{3}$. The combined carbonate washings were "back-extracted" four times with $50 \mathrm{ml}$. volumes of quinoline to minimize losses of glucuronide at this stage. The combined quinoline extracts were extracted with four successive volumes of $100 \mathrm{ml}$. $N / 10 \mathrm{NaOH}$, and the combined alkaline extracts, after acidification to $p H ~ 3.0$, were extracted once with $150 \mathrm{ml}$. and four times with $50 \mathrm{ml}$. volumes of butanol. The butanolic solution was washed four times with small volumes of water and evaporated to dryness under reduced pressure. The residue weighed $8.5 \mathrm{~g}$. and direct colorimetric assay (without hydrolysis) showed it to contain $1 \mathrm{~g}$. of combined oestriol. It should here be mentioned that colorimetric assays after hydrolysis with acid were conducted at all the preceding stages in the process. These showed that the losses of glucuronide in the discarded fractions were insignificant, but owing to the difficulty of attaining satisfactory hydrolysis, the figures have little real quantitative value and are therefore not reported.

The residue from the evaporation of the butanol was dissolved in about $50 \mathrm{ml}$. of methanol and after heating nearly to boiling the $p \mathrm{H}$ of the solution was adjusted to $7 \cdot 0-7 \cdot 5$ by the careful addition of saturated methanolic $\mathrm{NaOH}$. The solution was then slowly evaporated to about $30 \mathrm{ml}$. under a stream of nitrogen, by which time a heavy greyish crystalline precipitate had settled out. After chilling, this was filtered off and washed with about $20 \mathrm{ml}$. of cold methanol. The product weighed $0.654 \mathrm{~g}$. and melted at $264-265^{\circ}$ (decomposition and evolution of gas) after preliminary shrinking at $239-240^{\circ}$. No more precipitate could be obtained by further concentrating the filtrate.

The crude crystals were extracted repeatedly with small volumes of hot anhydrous methanol until all but a small amount of dark material was in solution. The combined methanolic extracts were then concentrated slowly under nitrogen to about $60 \mathrm{ml}$. After chilling, filtering and washing with cold methanol, $0.313 \mathrm{~g}$. of material, M.P. $298-299^{\circ}$ (decomposition and evolution of gas) with slight browning at $265-270^{\circ}$, was obtained. After drying at $80^{\circ}$ in vacuo over $\mathrm{P}_{2} \mathrm{O}_{5}$, the M.P. was raised to $305-306^{\circ}$. Further concentration of the methanolic filtrate yielded a further $0 \cdot 15 \mathrm{~g}$. of crystals of the same degree of purity and $0.038 \mathrm{~g}$. with a slightly lower M.P.

\section{Properties of the sodium salt.}

Analyses were carried out by Dr Schoeller on material obtained from batch 9, M.P. $305-306^{\circ}$. Found: C, 58.27, 58.19; H, 6.51, 6.43; Na, $4 \cdot 78 \%$. Calculated for $\mathrm{C}_{24} \mathrm{H}_{31} \mathrm{O}_{9} \mathrm{Na}, 0.5 \mathrm{CH}_{3} \mathrm{OH} ; \mathrm{C}, 58 \cdot 57 ; \mathrm{H}, 6 \cdot 62 ; \mathrm{Na}, 4.58 \%$.

Oestriol content (direct colorimetric assay)-Found: $55 \cdot 0,56 \cdot 7,58 \cdot 3 \%$. Calculated for $\mathrm{C}_{24} \mathrm{H}_{31} \mathrm{O}_{9} \mathrm{Na}, 0.5 \mathrm{CH}_{3} \mathrm{OH}: 57 \cdot 4 \%$.

$1.2 \mathrm{mg}$. gave a positive Tollens's naphthoresorcinol test. $0.21 \mathrm{mg}$. gave a positive Millon's test in the cold. $0 \cdot 21 \mathrm{mg}$. gave a negative Benedict's test. $0.21 \mathrm{mg}$. after heating at $120^{\circ}$ for 1.5 hours with $N / 10 \mathrm{HCl}$ and neutralizing gave a positive Benedict's test.

In the case of certain batches the methanol used for the crystallization was not anhydrous. The product after drying at $80^{\circ}$ in vacuo over $\mathrm{P}_{2} \mathrm{O}_{5}$ had M.P. 256-257 ${ }^{\circ}$ (decomposition and evolution of gas) after shrinkage at $242^{\circ}$. (Found (Schoeller): C, 56.33, 56.15\%; H, 6.68, 6.68\%; Na, 4.32\%. Calculated for 
$\mathrm{C}_{24} \mathrm{H}_{31} \mathrm{O}_{9} \mathrm{Na}, 1 \cdot 5 \mathrm{H}_{2} \mathrm{O} ; \mathrm{C}, 56 \cdot 14 \% ; \mathrm{H}, 6.68 \%$; $\mathrm{Na}, 4.48 \%$.) After two crystallizations of this material from anhydrous methanol, the M.P. was raised to 301-302 ${ }^{\circ}$. Mixed with directly isolated material of M.P. $305-306^{\circ}$, the M.P. was $304-305^{\circ}$. Directly isolated material of M.P. $305-306^{\circ}$ was dissolved in water and evaporated to dryness under a stream of nitrogen. The product had M.P. 258- $259^{\circ}$ which was unchanged by admixture with the directly isolated lowermelting compound.

The optical rotation of the sodium salt (M.P. 305-306 ${ }^{\circ}$ ) was determined in a Fischer micro-tube. Owing to the opalescence of the aqueous solution, the concentration had necessarily to be low. The observed rotations were therefore small, making very great accuracy impossible. $c=0.4966$ (water), $\alpha=-0.07^{\circ}$, $[\alpha]_{5461}^{28^{\circ}}=-28 \cdot 2^{\circ} ; c=0.5027$ (water), $\alpha=-0.052^{\circ},[\alpha]_{5461}^{22^{\circ}}=-21 \cdot 0^{\circ}$.

Ultraviolet absorption spectrum of oestriolglucuronide in alkaline solution.

The following experiment was carried out by Dr R. K. Callow of the National Institute for Medical Research, London. $5 \mathrm{ml}$. of a $0.02 \%$ aqueous solution of

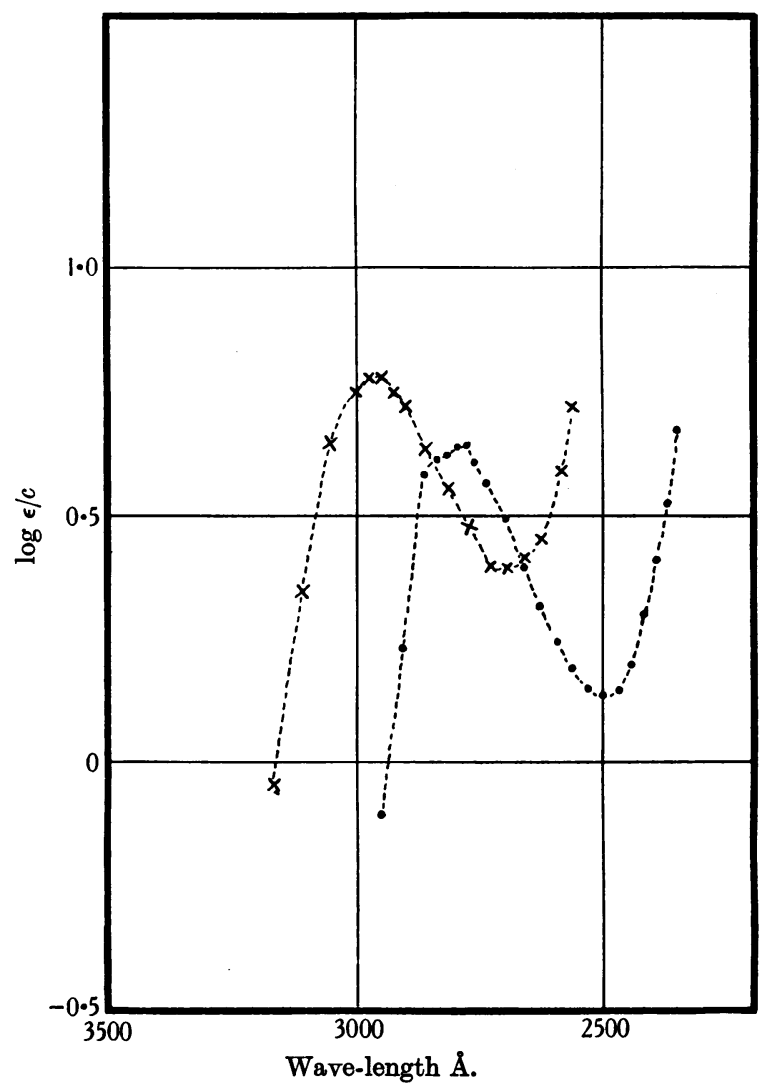

Fig. 1. -...- Oestriolglucuronide, $0 \cdot 0182 \%$ neutral aqueous solution. $\times \ldots \times$ Oestriolglucuronide, $0.0182 \%$ solution in $0.0091 \mathrm{~N} \mathrm{NaOH}$.

the sodium salt of oestriolglucuronide (M.P. 303-304 ${ }^{\circ}$ ) were diluted with $0.5 \mathrm{ml}$. of water and photographed. A second $5 \mathrm{ml}$. were diluted with $0.5 \mathrm{ml}$. of $\mathrm{N} / 10$ 
$\mathrm{NaOH}$ and photographed. The results are shown in Fig. 1 in which $\log \epsilon / c$ is plotted against wave-length, and where $\epsilon$ is the extinction coefficient as defined by the equation:

$$
\epsilon=\frac{1}{d} \log _{10}\left(\frac{\text { incident light }}{\text { transmitted light }}\right)-\epsilon_{0},
$$

and $c$ is the concentration in g. per litre.

The authors are also indebted to Dr Callow for the following information: "... assuming no interference with the absorption of the oestriol part of the molecule, the difference in intensity of absorption between oestriol and its glucuronide corresponds to an oestriol content of $\mathbf{5 7 . 5 \%}$ in the latter." (Calc. for $\mathrm{C}_{24} \mathrm{H}_{31} \mathrm{O}_{9} \mathrm{Na}, 0 \cdot 5 \mathrm{CH}_{3} \mathrm{OH}$ : oestriol, $57 \cdot 4 \%$.)

\section{Isolation of oestriol monomethyl ether from the hydrolysis products of methylated oestriolglucuronide.}

$171 \mathrm{mg}$. of the sodium salt of oestriolglucuronide were dissolved in $40 \mathrm{ml}$. of $\mathrm{N} \mathrm{NaOH}$ and shaken at intervals for 24 hours, methyl sulphate being added in small portions from time to time. No attempt was made to isolate and purify the bulky flocculent precipitate which separated at this stage. A preliminary experiment suggested that hydrolysis at $p \mathrm{H} 1.0$ for 2 hours at $120^{\circ}$ caused too extensive destruction to permit the isolation of the hydrolysis product in a state of purity. Milder conditions were therefore employed. The whole methylation mixture was acidified with $\mathrm{HCl}$ to $p \mathrm{H} 1.5$ and heated at $100^{\circ}$ for 5 hours. The mixture was cooled and then repeatedly extracted with ether. The ethereal extract was washed several times with $\mathrm{N} \mathrm{NaOH}$, then with water and finally evaporated to dryness. The product was a dark greenish blue semicrystalline solid and weighed $16.4 \mathrm{mg}$. The aqueous phase from the ether extraction was combined with the $\mathrm{NaOH}$ washings and rehydrolysed for 4 hours at $p \mathrm{H} \mathrm{1.2}$. The mixture was worked up as before, yielding a further $24.5 \mathrm{mg}$. of material similar to that obtained from the first hydrolysis.

The products were combined, boiled twice with charcoal in alcoholic solution, whereby all but a trace of the blue colour was removed, and recrystallized twice from $40 \%$ ethanol. The product crystallized in hexagonal plates identical in appearance with authentic oestriol monomethyl ether crystallized from the same mixture. The M.P. was $165-168^{\circ}$, which was unchanged after admixture with authentic oestriol monomethyl ether of M.P. $166-168^{\circ}$.

\section{Biological assay of the sodium salt of oestriolglucuronide.}

The method of Marrian \& Parkes [1929] was employed. Aqueous solutions of the sodium salt of different concentrations were injected into groups of twenty adult ovariectomized mice. The mice were injected at 9 a.m. and 5 p.m. on the first and second days, the volume of each injection being $0.1 \mathrm{ml}$. Vaginal smears were taken at 9 a.m., 5.30 p.m. and 11 p.m. on the third and fourth days, at 9 a.m. and 5.30 p.m. on the fifth day and at 9 a.m. on the sixth day. The smears were stained with methylene blue before examination. A smear from which leucocytes were absent and in which cornified cells were present was deemed to be positive. That is to say a smear consisting of mixed nucleated epithelial cells and cornified cells was counted as a positive, while a pure nucleated smear was counted negative. The occasional "doubtfully positive" smears have been counted as half positives. It is necessary to emphasize these points, since it appears reasonably certain that the great differences which have been reported in different laboratories for the potency of oestriol are mainly due to the different criteria which are accepted for a positive vaginal reaction. 
Similar tests were carried out at the same time with a highly purified specimen of oestriol. The curves obtained by plotting the percentage positive response of each group of mice against the quantity injected are shown in Fig. 2. The mouse unit is defined as the amount necessary to produce a $50 \%$ response.

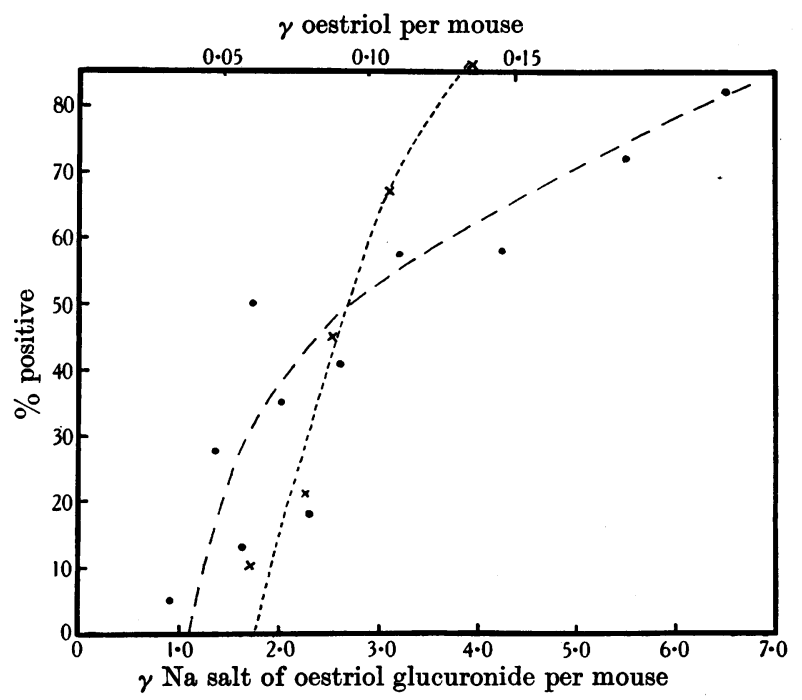

Fig. 2. $\times \ldots \times$ Oestriol. - - - $-\mathrm{Na}$ salt of oestriolglucuronide.

\section{SUMMARY.}

1. An improved method for the isolation of the crystalline sodium salt of oestriolglucuronide from human pregnancy urine is described. Yields as high as $500 \mathrm{mg}$. from 30 litres have been obtained.

2. Crystallization of the crude sodium salt from anhydrous methanol yields a product, M.P. about $305^{\circ}$ (decomposition and evolution of gas), which gives analytical figures corresponding to a composition $\mathrm{C}_{24} \mathrm{H}_{31} \mathrm{O}_{9} \mathrm{Na}, 0.5 \mathrm{CH}_{3} \mathrm{OH}$. Crystallization from methanol containing traces of water yields a product, M.P. about $256^{\circ}$ (decomposition and evolution of gas), which analysed to $\mathrm{C}_{24} \mathrm{H}_{31} \mathrm{O}_{9} \mathrm{Na}, 1 \cdot 5 \mathrm{H}_{2} \mathrm{O}$.

3. Spectrographic evidence provided by $\mathrm{Dr} \mathrm{R}$. K. Callow confirms the suggestion previously made that the phenolic hydroxyl of the oestriol is free in the glucuronide. Further confirmation of this was provided by isolating oestriol monomethyl ether from the hydrolysis products of the methylated glucuronide.

4. Tested on adult ovariectomized mice, the sodium salt of the glucuronide showed a potency of 370 m.u. per mg. Oestriol tested under the same conditions showed a potency of $10,700 \mathrm{~m} . \mathrm{u}$. per $\mathrm{mg}$.

The authors are greatly indebted to Dr M. Watson of the Department of Obstetrics and Gynaecology and to Miss Cassels of the Department of Social Service, Toronto General Hospital, for their co-operation in the collection of urine. They also wish to acknowledge gratefully the help given by Miss Dorothy Skill in much of the experimental work.

\section{REFERENCES.}

Callow (1936). Biochem. J. 30, 906.

Cohen \& Marrian (1936). Biochem. J. 30, 57.

- Marrian \& Watson (1935). Lancet, i, 674.

Marrian \& Parkes (1929). J. Physiol. 67, 399. 